\title{
Preventing Social Isolation in Older People
}

DOI:

10.1016/j.maturitas.2018.04.014

\section{Document Version}

Accepted author manuscript

Link to publication record in Manchester Research Explorer

\section{Citation for published version (APA):}

Cotterell, N., Buffel, T., \& Phillipson, C. (2018). Preventing Social Isolation in Older People. Maturitas.

https://doi.org/10.1016/j.maturitas.2018.04.014

\section{Published in:}

Maturitas

\section{Citing this paper}

Please note that where the full-text provided on Manchester Research Explorer is the Author Accepted Manuscript or Proof version this may differ from the final Published version. If citing, it is advised that you check and use the publisher's definitive version.

\section{General rights}

Copyright and moral rights for the publications made accessible in the Research Explorer are retained by the authors and/or other copyright owners and it is a condition of accessing publications that users recognise and abide by the legal requirements associated with these rights.

\section{Takedown policy}

If you believe that this document breaches copyright please refer to the University of Manchester's Takedown Procedures [http://man.ac.uk/04Y6Bo] or contact uml.scholarlycommunications@manchester.ac.uk providing relevant details, so we can investigate your claim.

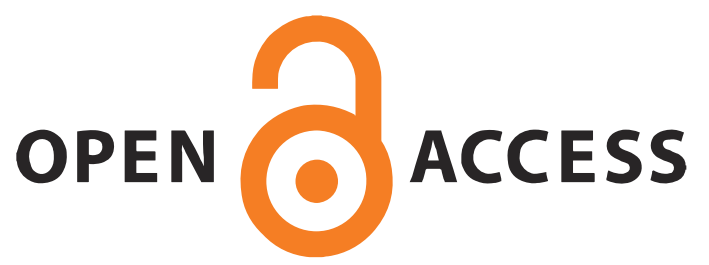




\section{Accepted Manuscript}

Title: Preventing Social Isolation in Older People

Authors: Natalie Cotterell, Tine Buffel, Christopher Phillipson

PII:

DOI:

S0378-5122(18)30163-4

Reference: https://doi.org/10.1016/j.maturitas.2018.04.014

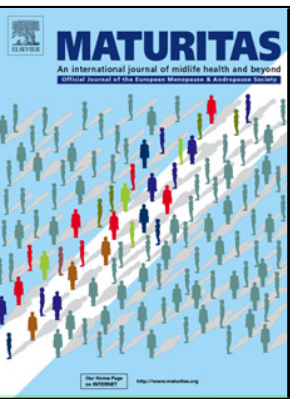

MAT 7001

To appear in: $\quad$ Maturitas

Received date: $\quad$ 2-3-2018

Revised date: $\quad 25-4-2018$

Accepted date: $\quad$ 27-4-2018

Please cite this article as: Cotterell Natalie, Buffel Tine, Phillipson Christopher.Preventing Social Isolation in Older People.Maturitas https://doi.org/10.1016/j.maturitas.2018.04.014

This is a PDF file of an unedited manuscript that has been accepted for publication. As a service to our customers we are providing this early version of the manuscript. The manuscript will undergo copyediting, typesetting, and review of the resulting proof before it is published in its final form. Please note that during the production process errors may be discovered which could affect the content, and all legal disclaimers that apply to the journal pertain. 


\title{
Preventing Social Isolation in Older People
}

Natalie Cotterell $^{a^{*}}$, Tine Buffel ${ }^{\mathrm{a}}$, Christopher Phillipson ${ }^{\mathrm{a}}$

a Manchester Institute for Collaborative Research on Ageing, School of Social Sciences, The University of Manchester, Manchester, M13 9PL, United Kingdom.

Email addresses: natalie.cotterell@postgrad.manchester.ac.uk (N. Cotterell), tine.buffel@manchester.ac.uk (T. Buffel), christopher.phillipson@manchester.ac.uk (C. Phillipson).

*Natalie Cotterell: Corresponding author at The University of Manchester School of Social Sciences, Manchester Institute for Collaborative Research on Ageing, Humanities Bridgeford St. Building, Manchester, M13 9PL, United Kingdom.

Contact details: +44 (0)7887427956.

\section{Highlights}

- Prolonged social isolation has harmful economic, health, and social consequences.

- Scientific evidence regarding the prevention of isolation in later life is limited.

- A life-course perspective helps identify and prevent isolation at key life stages.

- Research must consider the implications of greater diversity in older populations.

- A cultural change from 'cure' to 'prevention' of social isolation is required.

\begin{abstract}
The extent of social isolation amongst older people has emerged as a major concern for health and social policy. Although the social and health outcomes of social isolation are well documented, evidence regarding the prevention of isolation in later life remains scarce. This article addresses this by presenting the findings from a literature review focusing on the identification, assessment, prevention, and intervention strategies relevant to social isolation in older age. The paper first addresses the issues of identification and assessment, using an ecological framework to identify the risk factors for social isolation at four levels: individual, relationship, community, and societal. It then reviews different types of interventions to reduce or prevent social isolation in later life, including one-to-one, group, service provision, technology-based, neighbourhood, and structural interventions. The paper discusses both the opportunities and the constraints associated with these different approaches. The discussion highlights future directions for research, emphasising the need for a cultural change from 'cure' to 'prevention' of social isolation across the life-course, and the importance of acknowledging greater diversity within the ageing population.
\end{abstract}


Keywords: aging, loneliness, prevention, social isolation

\section{Introduction}

\subsection{What is social isolation?}

Social isolation can be defined as an objective measure reflecting an individual's lack of contacts or ties with others, such as family, friends, acquaintances and neighbours [1]. Social isolation is characterised as an absence or limitation in the quantity of social interactions. It is distinct from the related and subjective concept of loneliness which occurs when there is a perceived discrepancy between an individual's desired and achieved level of social interaction [1].

\subsection{Why is tackling social isolation important?}

Social isolation has been linked with a range of health problems in middle and later life. Individuals who are socially isolated have been found to be at greater risk of developing cardiovascular disease [2], stroke [2], depression [3], dementia [4], and premature death [5]. The mechanisms underlying the impact of social isolation on health remain unclear but are thought to include influences on health behaviours, sleep, exhaustion, and social connectedness [6]. Social isolation affects both individuals and the wider community. Health issues arising from isolation and loneliness lead to an increased use of health and social care services, and a higher number of emergency admissions and GP consultations [7].

This review of the literature on social isolation covers four main areas: first, identifying those at risk of isolation in middle and later life; second, methods for assessing isolation; third, developing interventions aimed at preventing isolation; and, fourth, future directions for research.

\section{Methods}

This review article presents current knowledge of how social isolation can be prevented in older age. PubMed, PsycINFO, EMBASE, ScienceDirect, and CINAHL were searched for relevant articles using the following key terms: social isolat*, lonel*, social connect*, OR social relations AND reduc*, minimi*, less*, OR prevent*. Only publications written in English were included.

\section{Identifying those at risk of social isolation}

Social isolation often remains undetected as it is not routinely assessed in settings (such as primary care) that are well-placed to identify individuals who are at risk [8]. This section addresses the importance of increasing awareness of social isolation as it develops across the life-course and the central role of frontline professionals in assessing and referring high-risk individuals to appropriate interventions.

\subsection{Risk factors for social isolation}

Most individuals experience feelings of loneliness or isolation at some point in their lives, although such moods may be transient with no long-lasting consequences. However, for some people they can persist with harmful effects on physical and mental health [9]. To understand 
the risk factors associated with isolation, it is useful to place the discussion within the context of an ecological framework [10]. This views social isolation as the outcome of interaction among multiple factors at four levels: individual, relationship, community, and societal (see Figure 1).

At the individual level, certain personal characteristics and life-course transitions have been associated with a higher risk of social isolation. The former includes: being 75 years and over [11], living or spending a significant amount of time alone [11], having limited financial resources [12], having psychological vulnerabilities such as a learning disability [13], belonging to certain minority groups [14], language barriers [15, 16], and having no children $[1,16]$. Life-course transitions associated with social isolation include: a decline in general health including poor vision or loss of hearing $[11,12]$, physical disability or loss of mobility [12], receiving a diagnosis of dementia [17], retirement [18], loss of income [12], losing the ability to drive [19], moving to a care home [12, 18], losing a partner [18], becoming a caregiver [18], and having children leave home especially if they move a long distance away [11].

At the relationship level, personal relationships and social networks influence the risk of becoming socially isolated. For example, an individual who has little contact with friends and family is more likely to become isolated [20]. Moreover, individuals who have poor quality personal relationships or those who experience regular conflict, disruption, or dysfunction are also at increased risk [20].

At the community level, the contexts in which social relations occur influence the risk of becoming socially isolated. The community level factors that are associated with an increased risk of isolation are: living in socially disadvantaged areas [11], high levels of neighbourhood crime [8], high residential mobility [8], limited opportunities to participate in social activities [21], and limited access to services, amenities, and public transport [22].

At the societal level, structural factors influence whether social participation is encouraged or inhibited. The factors that increase an individual's risk of becoming socially isolated are: experiencing discrimination and marginalisation [23], having economic and social policies that produce and maintain socioeconomic inequalities [8], a lack of social cohesion [16], and social norms which discourage social activity [24].

[Figure 1 to be inserted here]

\subsection{Using assessment tools}

Frontline professionals working in primary care or social work, as well as community workers, are well-placed to identify individuals who may be at risk. The 'Making Every Contact Count (MECC)' approach encourages frontline workers to have brief conversations with individuals about how they can make positive improvements to their own wellbeing [25]. This can act as an initial assessment of an individual's risk of isolation, helping professionals or community workers to decide whether onward referral is appropriate. The MECC approach is practical as it can fit into existing clinical practice, whilst promoting community cohesion.

If an individual is considered at high risk of social isolation, further information may also be collected using validated assessments tools such as: the Lubben Social Network Scale [26], 
Duke Social Support Index [27], and the Social Disconnectedness Scale [28]. These measure the size, closeness, and frequency of contact between the individual and their social networks. However, they are designed for use in research and may be unsuitable for use within the community or high-pressure work environments such as healthcare settings. Moreover, quantitative scales often unintentionally neglect certain issues, for example, men are less likely to report being isolated due to the stigma attached to feeling lonely [29]. There is therefore a need to develop practical assessment tools that provide an accessible method for identifying those at risk of social isolation. Nicholson [8] suggests that conducting qualitative interviews may be useful in choosing the most appropriate referral that will suit an individual's specific needs.

The risk of social isolation might also be examined at an area-level, reflecting the influence of neighbourhoods on health and social relationships. There have been several attempts to map the relative risk of isolation and loneliness across neighbourhoods. For example, Lucy and Burns [30] devised a spatial composite index that determined the areas of a London borough with the highest risk of loneliness and associated health risks. By encouraging local authorities to proactively index and spatially visualise where social isolation is most likely to occur, preventative policies can be targeted in areas which have especially vulnerable populations [30].

\section{Interventions tackling social isolation}

The need to identify and prevent social isolation and loneliness has been explored at a variety of levels, with the development of five main types of interventions: working with individuals, groups, services, neighbourhoods, and social structures. These will now be reviewed in turn, with summaries of the advantages and disadvantages of each approach.

\subsection{One-to-one interventions}

One-to-one interventions usually involve the pairing of an individual with a professional or volunteer, who regularly contact each other. Befriending schemes, where new friendships are formulated between an older adult and a volunteer who have common interests, are widely used in one-to-one interventions. Befriending has been found to have positive effects on health, helping people to reconnect with others [7, 31]. They also have the potential to be cost-effective and to benefit the volunteer befrienders, providing them with opportunities to maintain connections within their own communities [31]. However, there have been few attempts to measure levels of social isolation pre- and post-intervention. This limits the conclusions that can be drawn regarding the effectiveness of this approach. There is some evidence that befriending may be more effective with some social groups than others. For example, a systematic review concluded that this method significantly increased social support and reduced depression and anxiety in older adults with chronic health conditions [32]. This highlights the need for evaluating the impact of befriending on levels of social isolation among different groups of older adults.

Cross-sectional studies have found that feelings of loneliness and isolation are often associated with cognitive biases that promote negative thinking and social withdrawal [33]. Thus, psychological interventions have been used to enhance the ability of individuals to cope with negative feelings and re-engage with their social networks. A review by Gardiner et al. [34] reported that such approaches have had the most robust evaluation of different 
types of interventions, concluding that they successfully reduce social isolation. However, most of the identified interventions involved some degree of group interaction, making it difficult to separate individual and group factors in the success of the interventions. Moreover, the majority of studies used cross-sectional designs, thus causality cannot be inferred [7]. This limits the conclusions that can be made about the effectiveness of one-toone interventions in tackling and preventing social isolation.

\subsection{Group interventions}

Group interventions gather individuals around a common interest and can include social, educational, or physical activity sessions, group discussions, or group therapies. Several systematic reviews have found that group interventions that actively engaged individuals in the design, targeted specific groups, and included an educational and social aspect, were most effective at alleviating social isolation [7, 35]. However, none of the identified interventions included all of these aspects and there was significant heterogeneity in the interventions delivered. This limits the comparability of findings, making it difficult to confirm the active ingredients of effective group interventions.

Miyawaki [15] suggests that group-based activities may be particularly important for ethnic minority groups who share the same cultural values and who may have difficulty interacting with the wider community due to language or cultural barriers. Such interventions can enhance an individual's sense of belonging, whilst alleviating social isolation [16]. As an example, the New Beginnings Project in the UK used bilingual volunteers to increase social support for isolated refugees and migrants, building their confidence in interacting with the wider community [36]. However, there has been no evaluation of the impact of this programme on levels of social isolation, restricting any conclusions that can be drawn.

According to the Social Care Institute for Excellence [37] 'research evidence is particularly supportive of [...] group activities with a creative, therapeutic or discussion-based focus'. Mindfulness and stress reduction [38], reminiscence group therapy [39], and cognitive and social support interventions [40] have been used to alleviate feelings of isolation, enhancing social support and quality of life. Other examples of group interventions that have reduced social isolation include: discussion groups around health-related topics among women living alone; bereavement support for people recently widowed; and peer- and professionally-led discussion groups for adult children who are primary carers [7, 41].

\subsection{Service provision interventions}

Interventions in the context of existing service provision may offer advantages in ensuring that support can be sustained over the medium and long-term [7, 32]. Examples have included community navigator services where volunteers act as a link between hard-to-reach individuals and local services. For example, the 'Fit for the Future' programme involved 11 local Age UK services in England which integrated older people with long-term health conditions into existing local services and activities such as exercise groups. This resulted in individuals, particularly older carers, reporting that they felt less isolated [42].

Other service provision interventions have included students providing free computer training in retirement villages or care homes. Such interventions have successfully alleviated social isolation by connecting older adults to their friends and family online, whilst increasing younger adults' self-esteem and confidence [32, 37]. 


\subsection{Technology-based interventions}

Advances in and increasing usage of social technology among older people (e.g. e-mail, Skype calls) highlight the potential of this medium for combating social isolation in later life. Internet usage among individuals aged 65 to 74 years old living in the UK has increased from $52 \%$ in 2011 to $78 \%$ in 2017, with almost a third of those adults using social networking sites [43]. Other forms of technology such as smartphones and virtual assistants have changed the way individuals communicate and manage their daily activities. Future advances in virtual reality experiences, artificial intelligence, and robotics are also expected to enhance social connectivity and reduce isolation, especially for those with cognitive impairments.

Research has found that the internet, social networking sites, and smartphone technologies boost the number of opportunities to socially connect with others, whilst improving quality of life and alleviating loneliness among older adults [44]. Chopik [45] found that frequent use of social technology was associated with higher subjective health and wellbeing in older adults and lower depressive symptoms. The link between the frequency of use of social technology and these outcomes was mediated by reductions in loneliness. Other studies, however, have found no or only limited impact of technology use on health, loneliness, and social isolation [44].

A challenge associated with modern technology-based interventions is that individuals who are at a high risk of becoming severely socially isolated in later life may be amongst those least likely to have access to this medium. For example, $60 \%$ of care home residents in the UK reported that they had never used the internet, with just one fifth of care homes in England providing access to the internet [46].

\subsection{Neighbourhood interventions}

There is limited evidence about the effects of community development and neighbourhood interventions on reducing social isolation. However, the literature suggests that there is considerable potential in developing such approaches [47]. Many older people report difficulties in walking around their neighbourhood as an impediment to leaving their house and connecting with others. Greater availability of seating areas, safer pedestrian crossings, and priority seating on public transport make communities more accessible to older people and may be important in preventing social isolation [47]. The importance of this issue has been recognised by the World Health Organization (WHO) in their development of the concept of 'age-friendly cities and communities' (AFCCs) [47]. According to the WHO, an age-friendly environment is one which can provide a good place to grow old: '[it should] help people to remain independent for as long as possible, and provide care and protection when they are needed, respecting older people's autonomy and dignity' [48]. In 2010, the WHO formed the Global Network for AFCCs which by 2017 had a membership of 533 cities and communities, covering 158 million people across the global north and south [49].

\subsection{Structural interventions}

Structural interventions involve applying preventative strategies at the population level including promoting positive ageing through policy and attitudinal change. For example, the New Zealand Positive Ageing Strategy reinforces the Government's commitment to promote the participation of older people in communities [50]. The strategy outlines key goals including: implementing policies that support the employment of older workers such as 
providing family-friendly workplaces by recognising those with caring responsibilities and allowing flexible working hours; promoting mentoring programmes that harness the skills and experience of older people; and ensuring that training is available to all workers regardless of age [47]. Such government-level policies attempt to influence societal attitudes towards ageing by mandating behaviour change. This is important as public campaigns often encourage individuals to view older adults exclusively through a 'prism of vulnerability', meaning that many individuals believe that withdrawing from society is expected in later life. Government agencies have the power to change such misconceptions by ensuring that policies and campaigns portray positive images of older people, promoting social inclusion and preventing social isolation in older age.

\section{Future directions}

Based upon this review of the literature, several areas can be identified in terms of priorities for future research. Firstly, this paper suggests that a cultural change from cure to prevention of social isolation is required to successfully combat isolation in older age. Previous studies have aimed to reduce social isolation in adults aged 60 and over with limited success. This emphasises the importance of offering interventions at key transition points throughout the life-course, with the aim of building resilience for managing major changes associated with retirement, bereavement, and chronic ill-health [7, 8, 9]. Developing such an approach would allow stronger conclusions to be drawn regarding the most effective prevention strategies for different age groups.

Secondly, future research must acknowledge greater heterogeneity within the older population. Previous research has largely ignored diversity with only a limited number of studies exploring the specific forms of isolation experienced by ethnic or sexual minority groups. Future studies should compare determinants and interventions among individuals with different ethnicities, sexualities, and socioeconomic backgrounds to establish the predictors and optimum interventions for each group.

Thirdly, this paper confirms the importance of treating social isolation and loneliness as separate concepts, emphasising the need for future research to clearly define which dimensions of social relationships are being measured. Few studies distinguish between isolation and loneliness despite them having independent predictors and health effects [6]. This restricts the conclusions that can be made regarding the effectiveness of prevention strategies.

\section{Conclusion}

Previous interventions have often overlooked the potential effect of historical, cultural, and political contexts on levels of isolation. This review has highlighted the importance of adopting a more holistic approach in the application of an ecological perspective for understanding social isolation. Moreover, a shift from cure to prevention, and in how social isolation is perceived, is required to permit further exploration of its multi-dimensional characteristics. Although there is no one-size-fits-all solution for preventing social isolation, promoting the creation and maintenance of high quality social relationships throughout the life-course is vital. Furthermore, it is also important to promote social and emotional competence from an early age, with a focus on resilience building within communities. It is recommended that national, regional, and local authorities work together with communities to 
understand the context of social isolation across local areas, adapting interventions according to the needs of citizens. This will aid the prevention of social isolation, bringing associated social and economic benefits.

\section{Contributors}

Natalie Cotterell drafted the article.

Tine Buffel and Christopher Phillipson provided important intellectual content and contributed to revision of the draft manuscript.

\section{Conflict of interest}

The authors declare that they have no conflict of interest.

\section{Funding}

This work was supported by the European Commission through a Marie Curie Intra European Fellowship within the Seventh European Community Framework Programme (Grant No: 330354); by the Economic and Social Research Council (ESRC) under the Future Research Leaders scheme (Grant No: ES/N002180/1); and by the Humanities Strategic Investment Fund, The University of Manchester.

\section{Provenance and peer review}

This article has undergone peer review. 


\section{References}

1. De Jong Gierveld J, Van Tilburg TG, Dykstra PA. Loneliness and social isolation. In: Perlman D, Vangelisti A, editors. The Cambridge handbook of personal relationships, Cambridge: Cambridge University Press; 2006, p. 485-500.

2. Valtorta NK, Kanaan M, Gilbody S, Ronzi S, Hanratty B. Loneliness and social isolation as risk factors for coronary heart disease and stroke: systematic review and meta-analysis of longitudinal observational studies. Heart 2016; 102: 1009-1016.

3. Matthews GA, Nieh EH, Vander Weele CM, Halbert SA, Pradhan RV, Yosafat AS, et al. Dorsal raphe dopamine neurons represent the experience of social isolation. Cell 2016; 164: 617-631.

4. Kuiper JS, Zuidersma M, Voshaar RCO, Zuidema SU, van den Heuvel ER, Stolk RP, et al. Social relationships and risk of dementia: A systematic review and metaanalysis of longitudinal cohort studies. Ageing Res Rev. 2015; 22: 39-57.

5. Steptoe A, Shankar A, Demakakos P, Wardle J. Social isolation, loneliness, and allcause mortality in older men and women. Proc Natl Acad Sci. 2013; 110: 5797-5801.

6. Courtin E, Knapp M. Health and wellbeing consequences of social isolation and loneliness in old age: scoping review. Health Soc Care Community. 2015; 25: 799812.

7. Windle K, Francis J, Coomber C. Preventing loneliness and social isolation: interventions and outcomes. Social Care Institute for Excellence Research Briefing 39. London: SCIE; 2011.

8. Nicholson NR. A review of social isolation: an important but underassessed condition in older adults. J Prim Prev. 2012; 33: 137-152.

9. Qualter P, Vanhalst J, Harris R, Van Roekel E, Lodder G, Bangee M, et al. Loneliness across the life span. Perspect Psychol Sci. 2015; 10: 250-264.

10. Krug EG, Mercy JA, Dahlberg LL, Zwi AB. (2002). The world report on violence and health. Lancet. 2002; 360: 1083-1088.

11. Victor CR, Scambler SJ, Bowling ANN, Bond J. The prevalence of, and risk factors for, loneliness in later life: a survey of older people in Great Britain. Ageing Soc. 2005; 25: 357-375.

12. Savikko N, Routasalo P, Tilvis RS, Strandberg TE, Pitkälä KH. Predictors and subjective causes of loneliness in an aged population. Arch Gerontol Geriatr. 2005; 41: 223-233.

13. Lasgaard M, Nielsen A, Eriksen ME, Goossens L. Loneliness and social support in adolescent boys with autism spectrum disorders. J Autism Dev Disord. 2010; 40: 218-226.

14. Victor CR, Burholt V, Martin W. Loneliness and ethnic minority elders in Great Britain: an exploratory study. J Cross Cult Gerontol. 2012; 27: 65-78.

15. Miyawaki CE. Association of social isolation and health across different racial and ethnic groups of older Americans. Ageing Soc. 2015; 35: 2201-2228.

16. Platt L. Social activity, social isolation and ethnicity. Sociol Rev. 2009; 57: 670-702.

17. Rabin BS. Social networks and dementia. Lancet. 2000; 356: 76-77.

18. Victor C, Scambler S, Bond J, Bowling A. Being alone in later life: loneliness, social isolation and living alone. Rev Clin Gerontol. 2000; 10: 407-417.

19. Davey JA. Older people and transport: coping without a car. Ageing Soc. 2007; 27: 49-65.

20. Umberson D, Karas Montez J. Social relationships and health: A flashpoint for health policy. J Health Soc Behav. 2010; 51: 54-66. 
21. Toepoel V. Ageing, leisure, and social connectedness: how could leisure help reduce social isolation of older people? Soc Indic Res. 2013; 113: 355-372.

22. Lucas K. Transport and social exclusion: Where are we now?. Transp Policy. 2012 20: 105-113.

23. Visser MA, El Fakiri F. The prevalence and impact of risk factors for ethnic differences in loneliness. Eur J Public Health. 2016; 26: 977-983.

24. Lubben J. Addressing social isolation as a potent killer!. Public Policy Aging Rep. 2017; 27: 136-138.

25. Baird B, Charles A, Honeyman M, Maguire D, Das P. Understanding pressures in general practice. London: King's Fund; 2016.

26. Lubben J, Blozik E, Gillmann G, Iliffe S, von Renteln Kruse W, Beck JC, et al. Performance of an abbreviated version of the Lubben Social Network Scale among three European community-dwelling older adult populations. Gerontologist. 2006; 46: 503-513.

27. Landerman R, George LK, Campbell RT, Blazer DG. Alternative models of the stress buffering hypothesis. Am J Community Psychol. 1989; 17: 625-642.

28. Cornwell EY, Waite LJ. Social Disconnectedness, Perceived Isolation, and Health among Older Adults. J Health Soc Behav. 2009; 50: 31-48.

29. Dykstra PA. Older adult loneliness: myths and realities. Eur J Ageing. 2009; 6: 91100.

30. Lucy L, Burns L. Devising a Composite Index to Analyze and Model Loneliness and Related Health Risks in the United Kingdom. Gerontol Geriatr Med. 2017; 3: 1-10.

31. Cattan M, Kime N, Bagnall AM. The use of telephone befriending in low level support for socially isolated older people-an evaluation. Health Soc Care Community. 2011; 19: 198-206.

32. Siette J, Cassidy M, Priebe S. Effectiveness of befriending interventions: a systematic review and meta-analysis. BMJ open. 2017; 7: e014304.

33. Rotenberg KJ, Addis N, Betts, LR, Corrigan A, Fox C, Hobson Z, et al. The relation between trust beliefs and loneliness during early childhood, middle childhood, and adulthood. Pers Soc Psychol Bull. 2010; 36: 1086-1100.

34. Gardiner C, Geldenhuys G, Gott M. Interventions to reduce social isolation and loneliness among older people: an integrative review. Health Soc Care Community. 2018; 26: 147-157.

35. Dickens AP, Richards SH, Greaves CJ, Campbell JL. (2011). Interventions targeting social isolation in older people: a systematic review. BMC Public Health. 2011; 11: 647.

36. UK Community Foundations. New Beginnings: Funder Report. London: UK Community Foundations; 2018.

37. Social Care Institute for Excellence. At a glance 60: Preventing loneliness and social isolation among older people. [Internet] 2012; [cited 1 February 2018]. Available from https://www.scie.org.uk/publications/ataglance/ataglance60.asp.

38. Creswell JD, Irwin MR, Burklund LJ, Lieberman MD, Arevalo JM, Ma J, et al. Mindfulness-based stress reduction training reduces loneliness and pro-inflammatory gene expression in older adults: a small randomized controlled trial. Brain Behav Immun. 2012; 26: 1095-1101.

39. Liu SJ, Lin CJ, Chen YM, Huang XY. The effects of reminiscence group therapy on self-esteem, depression, loneliness and life satisfaction of elderly people living alone. Mid-Taiwan Journal of Medicine 2007; 12: 133-142. 
40. Saito T, Kai I, Takizawa A. Effects of a program to prevent social isolation on loneliness, depression, and subjective well-being of older adults: a randomized trial among older migrants in Japan. Arch Gerontol Geriatr. 2012; 55: 539-547.

41. Cattan M, White M, Bond J, Learmouth A. Preventing social isolation and loneliness among older people: a systematic review of health promotion interventions. Ageing Soc. 2005; 25: 41-67.

42. Wigfield A, Alden S, Kispeter E. Age UK's Fit for the Future social prescribing extension project evaluation report. Leeds: The University of Leeds, Centre for International Research on Care, Labour and Equalities; 2015.

43. Prescott C. Internet users in the UK: 2017. London, UK: The Office for National Statistics; 2017.

44. Czaja SJ. The role of technology in supporting social engagement among older adults. Public Policy Aging Rep. 2017; 27: 145-148.

45. Chopik WJ. The benefits of social technology use among older adults are mediated by reduced loneliness. Cyberpsychol Behav Soc Netw. 2016; 19: 551-556.

46. Age UK. The digital inclusion of older people in care homes: Learning and good practice from Reach for IT. London, UK: Author; 2013.

47. Buffel T, Handler S, Phillipson C, editors. Age-friendly communities: A global perspective. Bristol: Policy Press; 2018.

48. World Health Organization. World Report on Aging and Health. Geneva, Switzerland: Author; 2015.

49. Rémillard-Boilard S. The UK network of age-friendly communities: A general review. Working with Older People 2018; 22: 30-38.

50. Lianne D. New Zealand Positive Ageing Strategy. Wellington, New Zealand: The Ministry of Social Development; 2001. 
Figure 1. The ecological framework: examples of risk factors for social isolation at each level.

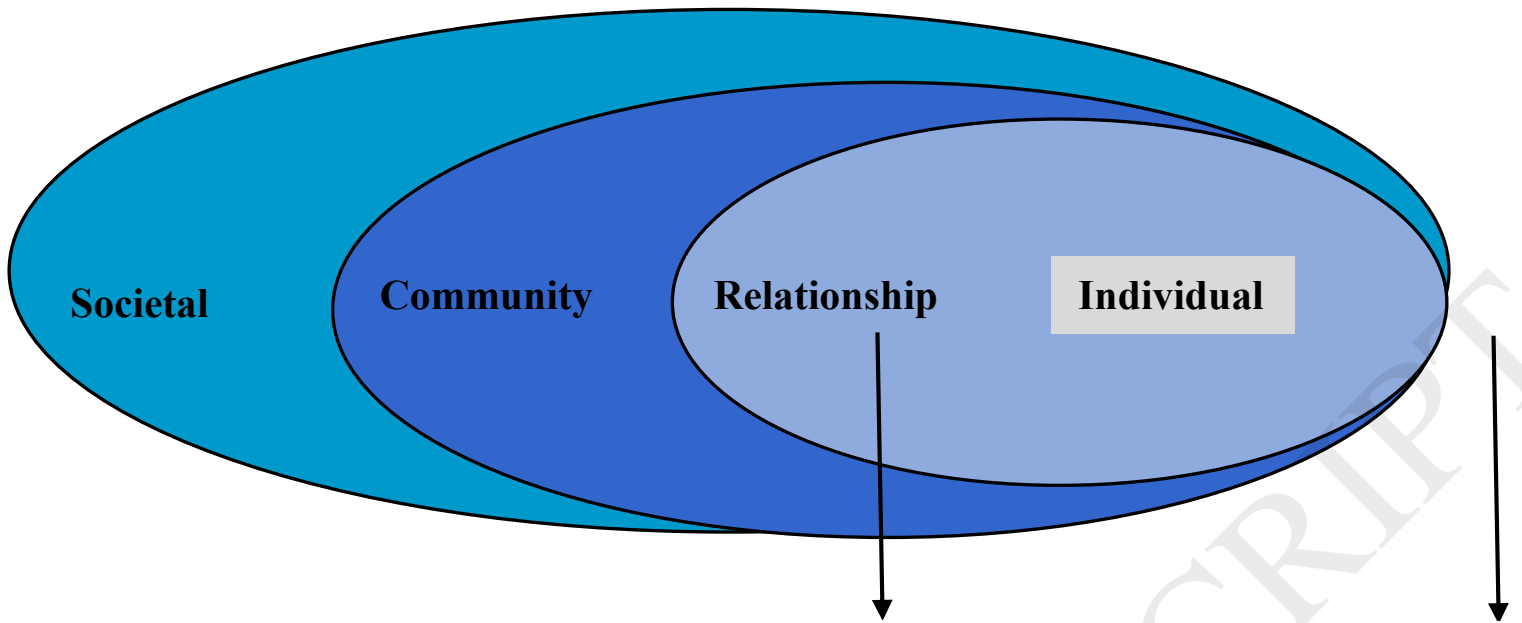

- Discrimination/ marginalisation

- $\quad$ Economic and social policies that maintain inequalities

- $\quad$ Lack of social cohesion

- $\quad$ Social norms
Living in an area with:

- Low income or social disadvantages

- High crime

- Limited opportunities for social participation

- $\quad$ High residential mobility

- $\quad$ Limited access to services, amenities, and public transport

Personal characteristics:

- $\quad$ Frequency of contact with friends/family/neighbours

- $\quad$ Size and quality of social network

- Family conflict, disruption, or dysfunction
- $\quad$ Being aged 75 years and over

- $\quad$ Living alone/spending significant amount of time alone

- Being widowed or divorced

- Having limited financial resources

- Having psychological vulnerabilities

- Belonging to certain minority groups

- $\quad$ Language barriers

- Having no children

Life-course transitions:

- Decline in general health including poor vision or loss of hearing

- Physical disability or loss of mobility

- $\quad$ Receiving diagnosis of dementia

- Retirement

- $\quad$ Loss of income

- $\quad$ Losing the ability to drive

- Moving to a care home

- Losing a partner

- Being a caregiver

- Having children leave the family home

- Having children who relocate a long distance away 